\title{
A study to assess the association of maternal factors and the outcome of pregnancy among mothers delivering in a tertiary care hospital in Haryana, India
}

\author{
Shveta Saini ${ }^{1}$, Mukhmohit Singh ${ }^{1}$, Anshu Mittal $^{2}$
}

\author{
${ }^{1}$ Assistant Professor, Department of Community Medicine, MMMC\&H, Kumarhatti, Solan, India \\ ${ }^{2}$ Professor, Department of Community Medicine, MMIMSR, Mullana, India
}

Received: 17 June 2016

Accepted: 21 June 2016

\author{
*Correspondence: \\ Dr. Shveta Saini, \\ E-mail: shveta.saini@gmail.com
}

Copyright: () the author(s), publisher and licensee Medip Academy. This is an open-access article distributed under the terms of the Creative Commons Attribution Non-Commercial License, which permits unrestricted non-commercial use, distribution, and reproduction in any medium, provided the original work is properly cited.

\begin{abstract}
Background: Low birth weight is a major cause of infant mortality and is considered as a sensitive index of the nation's health and development. World Health Organization (WHO) defines low birth weight (LBW) as weight at birth of less than 2,500 grams (up to and including 2499 grams) irrespective of the gestational age. LBW is the leading cause of neonatal and postnatal deaths and as such it remains a worldwide issue and one of the most important public health problems, particularly in developing countries. The objectives of the study were to study the outcome of pregnancy whether normal, low birth weight, or still-birth, and to study the association of maternal risk factorshaemoglobin level, diabetes mellitus, hypertension and outcome of pregnancy.

Methods: It was a cross sectional study carried out among the pregnant females delivering in MM Institute of Medical Sciences and Research, Mullana, Haryana, India from January 2010 to December 2010. A total of 500 cases were interviewed for the study purpose by systematic random sampling, using a semi structured pretested questionnaire. Data was analyzed using SPSS17 software.

Results: Outcomes of pregnancy recorded were $28.8 \%$ low birth weight, $5.4 \%$ stillbirth and $65.8 \%$ normal birth weight. The mean birth weight was recorded as $2.556 \pm 0.411 \mathrm{kgs}$. The incidence of LBW was maximum $(54.3 \%)$ among the mothers who did not seek ANC while it was minimum (12.7\%) in the ones who had sought ANC for more than 3 times. $57.6 \%$ mothers were anaemic and severe anaemia in $1.4 \%$ contributed towards more number of stillbirths and LBW infants $(57.14 \%$ and $42.86 \%$ respectively). $4.2 \%$ mothers were found to be suffering from pregnancy induced hypertension (PIH). $69.41 \%$ of the mothers with any infection had delivered a low birth weight baby and $4.70 \%$ had a stillborn baby.

Conclusions: The present study confirms birth weight as an important determinant of neonatal and post-neonatal outcomes.
\end{abstract}

Keywords: Low birth weight, Pregnancy induced hypertension, Pregnancy outcome, Stillbirth, Diabetes mellitus, ANC

\section{INTRODUCTION}

Pregnancy and childbirth are generally times of joy for parents and families. Pregnancy, birth and motherhood, in an environment that respects women, can powerfully affirm women's rights and social status without jeopardizing their health. ${ }^{1}$ The type of maternity care which the mother gets during the course of her pregnancy determines the various outcomes of pregnancy. A multifactorial relationship exists between the 
environment, health and nutritional status, social status of a woman and the growth of the foetus. All women, whether their pregnancies are complicated or not, need good quality maternal health services during pregnancy, delivery and in the post-partum period to ensure their health and that of their infants. ${ }^{2}$

World Health Organization (WHO) defines low birth weight (LBW) as weight at birth of less than 2,500 grams (up to and including 2499 grams) irrespective of the gestational age. ${ }^{3}$ It is well recognized that low birth weight $(\mathrm{LBW})$ is one of the most important factors in infant mortality, as mortality of LBW babies is 40 times more than the normal-weight babies.

Moreover, it has been shown that low birth weight could predispose individuals to cardiovascular risk factors, such as hypertension, diabetes and obesity. Thus, the infant born with a birth weight under $2500 \mathrm{gm}$ could be an 'at risk' individual for life. LBW is the leading cause of neonatal and postnatal deaths and as such it remains a worldwide issue and one of the most important public health problems, particularly in developing countries. ${ }^{4}$ Moreover, it has been shown that low birth weight could predispose individuals to cardiovascular risk factors, such as hypertension, diabetes and obesity. Thus, the infant born with a birth weight under 2500 gm could be an 'at risk' individual for life. ${ }^{5}$

The birth weight of an infant is dependent on the length of the gestation and the intrauterine growth of the fetus. LBW can result from preterm birth or intrauterine growth restriction (IUGR) or a combination of the two. It is generally assumed that prevention of IUGR and in-turn, prevention of LBW results in a corresponding reduction in perinatal mortality. ${ }^{6}$ Like low birthweight, it is also associated with maternal under-nutrition and ill health, among other factors. Preterm birth is also of significant public health importance because of its association with an increase in mortality and childhood morbidities such as developmental problems, cerebral palsy, learning difficulties, and an increased risk of sudden infant deaths. ${ }^{7}$ These are the babies born too early, before 37 weeks of gestation. Their intrauterine growth may be normal. That is, their weight, length and development may be within normal limits for the duration of gestation. Given good neonatal care, these babies can catch up growth and by 2 to 3 years of age will be of normal size and performance. ${ }^{8}$

According to $\mathrm{WHO}$, the prevalence of low birth weight is estimated to be $15 \%$ worldwide with a range of $3.3-38 \%$ and occurs mostly in developing countries. ${ }^{9}$ For India, National Family Health Survey-3 (NFHS-3) data reveals that $72 \%$ of deliveries took place at home during the survey period from 2005-2006. Out of these only 34\% of births were weighed at birth, and over one in five $(22 \%)$ were of low birth weight (less than $2.5 \mathrm{~kg}$ ). ${ }^{10}$ In spite of consistent efforts to improve the quality of maternal and child health LBW rate is still quite high. Many factors affect the duration of gestation and fetal growth, and thus, the birthweight. It has been known that majority of the maternal factors that are contributing to adverse perinatal outcome are preventable and are called "preventable risk factors". The maternal factors include malnutrition, severe anemia, heavy physical work during pregnancy, hypertension, malaria, toxemia, smoking, low socioeconomic status, short maternal stature, very young age, high parity, close birth spacing low education status and antenatal care during pregnancy.

Most importantly, added to malnutrition, too many and too frequent pregnancies contribute to the continued depletion of mother's body. ${ }^{11}$ Early and good prenatal care increases the chances of having a healthy baby and provides an array of medical, nutritional and educational interventions. ${ }^{12}$ The type of antenatal care that is required for a healthy outcome of pregnancy is already available in the country and is provided at the grass-root level through a network of anganwadi centers, sub-centers, primary health centers, community health centers, district hospitals, and medical colleges. However, due to inadequate utilization of these services, a normal pregnancy can take the path of "at-risk pregnancy" at any gestational age. This is especially true for the rural and the under-privileged and the socio-economically weaker sections of our society.

Maternal and infant health has been established as a top most priority in the health care system worldwide. Low birth weight being the root cause of all adverse perinatal outcomes needs special attention. Low birth weight is a topic of major concern in India. Since, Haryana state accounts for a major proportion of low birth weight babies nationwide, so it becomes imperative to study the distribution and determinants of low birth weight babies. It is an established fact that a large number of home deliveries conducted in the rural areas because of cultural beliefs and underutilization of the antenatal care services leads to gross under-reporting of births weights along with other related parameters, making it difficult to correctly estimate the burden of morbidity in the community.

Hence, it becomes important to study the associated, causal risk factors for low birth weight and other pregnancy outcomes in a hospital set up facilitating an authentic data for better understanding of web of possible associations and factors affecting the birth weight of the newborn. Keeping in mind the above said factors, the present study was conducted with the following objectives:

- To study the outcome of pregnancy whether normal, low birth weight, or still-birth.

- To study the association of maternal risk factorshaemoglobin level, diabetes mellitus, hypertension and outcome of pregnancy. 


\section{METHODS}

\section{Study area}

This study was undertaken in all the three units of obstetrics and gynaecology department of MM Institute of Medical Sciences and Research, Mullana, Haryana, India.

\section{Study design}

It was a cross sectional study carried out among the pregnant females delivering in the hospital.

\section{Study period}

The study continued for a period of twelve months from January 2010 to December 2010.

The inclusion criteria includes the study consisted of only those females who delivered after the completion of 28 weeks of gestation, irrespective of the outcome. Stillbirths were also included in the study. The exclusion criteria include all the pregnancies which terminated before the completion of $28^{\text {th }}$ week of gestation, irrespective of the outcome were excluded from the study. The females who did not give the consent for the study were also excluded.

A total of 500 cases were taken up for the study purpose as WHO recommends that the percentage of LBW be based on measurements on atleast 500 new born babies. ${ }^{13}$

\section{Sampling technique}

On an average, 150-200 deliveries, including normal, assisted and caesarean, take place in the hospital each month. Every fifth woman delivering in the hospital was taken up for the study purpose and thus a total of 500 women were taken up. These women were contacted and interviewed within last 24 hours of delivery to assess the association between maternal factors and the pregnancy outcome. In cases where the consent was not obtained due to any reason, the subsequent next case according to the delivery register of the labour room was taken for the study.

\section{Study tools}

A proforma with reference to the information being collected from each respondent was evolved and pretested on 30 newly delivered females. It was modified in the light of the experience gained during pretesting. The proforma was broadly categorized into following components:

- $\quad$ Socio-demographic profile of the mother.

- Medical history and family history.

- Obstetric history of present pregnancy.

- Outcome of pregnancy.
The available antenatal records and the documentation at the time of admission and delivery of the female were also consulted.

\section{Methodology}

An interview method was adopted to extract the desired information from the study participants. Before starting with the interview process, an informed consent was taken from each study participant.

\section{Data analysis}

Lastly, the data collected in respect of various variables was statistically analyzed by using statistical package SPSS 17.0. Chi square test was applied to see the association between the two attributes.

The study protocol was approved from the ethics committee of MMIMSR, Mullana, Ambala. Written informed consent was taken in local language from the study participants during the interview process.

\section{RESULTS}

With the motive of finding diverse pregnancy outcomes in relation to various maternal factors, the present study was conducted in the obstetrics and gynaecology department of MMIMSR, Mullana Ambala. The study included 500 mothers and they were interviewed within 24 hours of delivery by using a semi-structured questionnaire. Among the total mothers interviewed $(n=500), 18.8 \%$ mothers were teenagers and $15.8 \%$ mothers were over 30 years of age.

The mean birth weight came out to be $2.556 \mathrm{~kg}$ with a standard deviation of $0.411 \mathrm{~kg}$. Among the total births $(n=500)$, it was seen that the occurrence of adverse pregnancy outcome was $34.2 \%$ which included $28.8 \%$ low birth weight babies and $5.4 \%$ stillborn babies. About two third of the mothers $(65.8 \%)$ delivered a normal weight baby (Table 1).

\section{Table 1: Distribution of outcomes of pregnancy} among the mothers.

\begin{tabular}{|ll|l|}
\hline Outcome & Number & Percentage (\%) \\
\hline Low birth weight & 144 & 28.8 \\
\hline Stillbirth & 27 & 5.4 \\
\hline Normal birth weight & 329 & 65.8 \\
\hline Total & 500 & 100 \\
\hline
\end{tabular}

Mean birth weight- $2.556 \mathrm{~kg}$; SD $0.411 \mathrm{~kg}$.

Prevalence of LBW was recorded to be $28.8 \%$. Teenage mothers $(68.08 \%)$ contributed more towards LBW as compared to the older mothers $(64.55 \%)$, the difference being statistically significant $(\mathrm{p}<0.001)$ (Table 2$)$.

The incidence of LBW was maximum (54.3\%) among the mothers who did not seek ANC while it was 
minimum $(12.7 \%)$ in the ones who had sought ANC for more than 3 times (Table 3). Further, the incidence of low birth weight was found to be lesser among the mothers seeking ANC from a doctor $(21.5 \%)$ in comparison to
$42.2 \%$ when the antenatal care was provided by the ANM. These observations were found to be statistically highly significant ( $\chi^{2} 118.354$, df 8 , p value <0.0001).

Table 2: Pregnancy outcome according to age of the mother.

\begin{tabular}{|lllll|}
\hline Age (years) & Pregnancy outcome & & & Total \\
\hline$<20$ & Stillbirth & Low birth weight & Normal birth weight & $94(100 \%)$ \\
\hline $20-25$ & $15(15.95 \%)$ & $64(68.08 \%)$ & $15(15.95 \%)$ & $212(100 \%)$ \\
\hline $26-30$ & $2(0.94 \%)$ & $12(5.66 \%)$ & $198(93.39 \%)$ & $115(100 \%)$ \\
\hline$>30$ & $4(3.47 \%)$ & $17(14.78 \%)$ & $94(81.73 \%)$ & $79(100 \%)$ \\
\hline Total & $6(7.59 \%)$ & $51(64.55 \%)$ & $22(27.84 \%)$ & $500(100 \%)$ \\
\hline
\end{tabular}

$\left(\chi^{2} 123.6 ;\right.$ df $6 ; p$ value $\left.<0.001\right)$

Table 3: Association of pregnancy outcome and frequency of ANC visits.

\begin{tabular}{|lllll|}
\hline \multirow{2}{*}{ ANC frequency } & Pregnancy outcome & Low birth weight & Normal birth weight & Total \\
\hline No ANC & Stillbirth & $50(54.3 \%)$ & $23(25 \%)$ & $92(100 \%)$ \\
\hline Once & $19(20.7 \%)$ & $17(36.2 \%)$ & $30(63.8 \%)$ & $47(100 \%)$ \\
\hline Twice & $0(0 \%)$ & $28(31.1 \%)$ & $58(64.4 \%)$ & $90(100 \%)$ \\
\hline Thrice & $4(4.4 \%)$ & $36(21.3 \%)$ & $129(76.3 \%)$ & $169(100 \%)$ \\
\hline Four or more & $4(2.4 \%)$ & $13(12.7 \%)$ & $89(87.3 \%)$ & $102(100 \%)$ \\
\hline Total & $0(0 \%)$ & $144(28.8 \%)$ & $329(65.8 \%)$ & $500(100 \%)$ \\
\hline
\end{tabular}

Among the moderately anaemic mothers, stillbirths and low birth weight babies were $6.05 \%$ and $38.79 \%$ respectively and the normal birth weight babies were $55.16 \%$. The mothers with normal haemoglobin level showed remarkable results with only $2.83 \%$ stillbirths and $15.09 \%$ low birth weight babies. The incidence of normal birth weight babies was seen highest (82.07\%) among the mothers with normal haemoglobin level. Hence, a statistically significant association was found among the anaemic status of the mother and the pregnancy outcome, highlighting that, with an improvement in the haemoglobin level, the pregnancy outcome also improves (Table 4).

Table 4: Association of pregnancy outcomes and anaemic status of the mother.

\begin{tabular}{|lllll|}
\hline $\begin{array}{l}\text { Anaemic } \\
\text { status }\end{array}$ & Stillbirth & $\begin{array}{l}\text { Low } \\
\text { birth } \\
\text { weight }\end{array}$ & $\begin{array}{l}\text { Normal } \\
\text { birth } \\
\text { weight }\end{array}$ & Total \\
\hline Severe & 4 & 3 & 0 & 7 \\
& $(57.14 \%)$ & $(42.86 \%)$ & $(0)$ & $(100 \%)$ \\
\hline Moderate & 17 & 109 & 155 & 281 \\
& $(6.05 \%)$ & $(38.79 \%)$ & $(55.16 \%)$ & $(100 \%)$ \\
\hline $\begin{array}{l}\text { No } \\
\text { anaemia }\end{array}$ & 6 & 32 & 174 & 212 \\
\hline Total & $27.83 \%)$ & $(15.09 \%)$ & $(82.07 \%)$ & $(100 \%)$ \\
\hline & $(5.4 \%)$ & 144 & 329 & 500 \\
$(28.8 \%)$ & $(65.8 \%)$ & $(100 \%)$ \\
\hline
\end{tabular}

$\left(\chi^{2} 104.266\right.$; df 4 p value: 0.000$)$
Table 5: Pregnancy outcome in relation to pregnancy induced hypertension in mother.

\begin{tabular}{|lllll|}
\hline \multirow{2}{*}{ Hypertension } & \multicolumn{3}{l}{ Pregnancy outcome } \\
& Stillbirth & $\begin{array}{l}\text { Low } \\
\text { birth } \\
\text { weight }\end{array}$ & $\begin{array}{l}\text { Normal } \\
\text { birth } \\
\text { weight }\end{array}$ & Total \\
\hline \multirow{2}{*}{ Yes } & $\begin{array}{l}10 \\
(19 \%)\end{array}$ & 7 & 21 \\
& 23 & $134.6 \%)$ & $(33.3 \%)$ & $(100 \%)$ \\
\hline \multirow{2}{*}{ No } & $(4.8 \%)$ & $(28 \%)$ & 322 & 479 \\
& 27 & 144 & 329 & $(100 \%)$ \\
\hline \multirow{2}{*}{ Total } & $(5.4 \%)$ & $(28.8 \%)$ & $(65.8 \%)$ & $(100 \%)$ \\
& & & & 500 \\
\hline
\end{tabular}

$\left(\chi^{2} 13.768 ;\right.$ df $2 ; p$ value 0.001$)$

Among the study subjects, $4.2 \%$ mothers suffered from hypertension during pregnancy. These mothers showed a higher occurrence of adverse outcomes as compared to the non-hypertensive counterparts. Two thirds of mothers with hypertension resulted in stillbirths and low birth weight infants (19\% and $47.6 \%$ respectively) whereas it was only $4.8 \%$ and $28 \%$ respectively in the nonhypertensive mothers. This association was found to be statistically significant (Table 5).

Pre-existing diabetes mellitus in the mother did not seem to influence the occurrence of LBW. Among the known diabetics, $23.07 \%$ had LBW baby whereas only one mother encountered a stillbirth. However, the result was not statistically significant (Table 6). 
Table 6: Pregnancy outcome in relation to preexisting diabetes mellitus in the mother.

\begin{tabular}{|lllll|}
\hline $\begin{array}{l}\text { Diabetes } \\
\text { mellitus }\end{array}$ & Stillbirth & $\begin{array}{l}\text { Low } \\
\text { birth } \\
\text { weight }\end{array}$ & $\begin{array}{l}\text { Normal } \\
\text { birth } \\
\text { weight }\end{array}$ & Total \\
\hline \multirow{2}{*}{ Yes } & 1 & 3 & 9 & 13 \\
& $(7.69 \%)$ & $(23.07 \%)$ & $(69.23 \%)$ & $(100 \%)$ \\
\hline \multirow{2}{*}{ No } & 26 & 141 & 320 & 487 \\
& $(5.33 \%)$ & $(28.95 \%)$ & $(65.70 \%)$ & $(100 \%)$ \\
\hline \multirow{2}{*}{ Total } & 27 & 144 & 329 & 500 \\
& $(5.4 \%)$ & $(28.8 \%)$ & $(65.8 \%)$ & $(100 \%)$ \\
\hline
\end{tabular}

$\left(\chi^{2} 0.305 ;\right.$ df 2 p value: 0.858$)$
It was seen that among the total mothers with any infection during the course of their pregnancy $(n=85)$, more than two third $(69.41 \%)$ had delivered a low birth weight baby. In comparison, mothers with no infection had only one fifth $(20.48 \%)$ low birth weight babies and showed a favorable outcome with resulting $73.97 \%$ normal birth weight babies.

Hence it was concluded that the presence of any infection at any time during pregnancy led to adverse pregnancy outcomes as low birth weight and stillbirth. On statistical analysis, this association was found to be highly significant.

Table 7: Association of pregnancy outcome and infection in mothers during pregnancy.

\begin{tabular}{|c|c|c|c|c|}
\hline \multirow{2}{*}{ Infection } & \multicolumn{3}{|c|}{ Pregnancy outcome } & \multirow{2}{*}{ Total } \\
\hline & Stillbirth & Low birth weight & Normal birth weight & \\
\hline Yes & $4(4.70 \%)$ & $59(69.41 \%)$ & $22(25.88 \%)$ & $85(100 \%)$ \\
\hline No & $23(5.54 \%)$ & $85(20.48 \%)$ & $307(73.97 \%)$ & $415(100 \%)$ \\
\hline Total & $27(5.4 \%)$ & $144(28.8 \%)$ & $329(65.8 \%)$ & $500(100 \%)$ \\
\hline
\end{tabular}

\section{DISCUSSION}

The mean birth weight recorded in the study $(2.556 \pm 0.411 \mathrm{kgs})$ is in conformity with a mean birth weight of $2.53 \pm 0.424 \mathrm{~kg}$ reported by Kiran et al at $\mathrm{MCH}$ centers of Kasturba Hospital, Wardha Maharashtra, India. $^{14}$ Joshi et al in their hospital based study in Allahabad and Sachdeva et al in his study in Gujarat also reported the mean birth weight of all the new born babies to be $2.64 \pm 0.44 \mathrm{~kg}$ and $2.63 \pm 0.029 \mathrm{~kg}$ respectively. ${ }^{15,16}$ The prevalence of low birth weight was $28.8 \%$ in the present study which is lesser as compared to the NFHS-3 (2005-2006) figure for Haryana (32.7\%). Lower prevalence in the present study could be attributed to the fact that this being a tertiary care center study, all the newborns were accurately weighted at the time of birth while in the NFHS-317 survey for Haryana, estimated birthweight was available for $29.9 \%$ of the total newborns and the prevalence was then calculated through the written records or maternal recall. Further, increase in the antenatal coverage could also have led to a decrease in the prevalence of low birth weight in the present study. The high incidence of low birth weight babies among the teenage mothers in the present study could be because of social factors such as very young age at the time of marriage leading to early child bearing. Saxena et al in Safdarjang hospital in South Delhi also found more number of LBWs among the teenage mothers (33.9\%) as compared to $30 \%$ in older mothers; the difference not being statistically significant $(\mathrm{p}=0.413) .{ }^{18}$ Kiran et al also had similar findings in Wardha, Maharashtra and reported an increased incidence of LBW (41.5\%) among the teenage mothers as compared to mothers in age more than 30 years $(35 \%) .{ }^{14}$ The rate of stillbirths was also found to be higher among the teenage mothers (15.95\%) as compared to mothers of age 30 years and above
(7.59\%). Results were found to be similar to that of Sharma et al in a resettlement colony of east Delhi, who found that $15.6 \%$ of adolescents had stillbirths as compared to $1.3 \%$ of adult mothers. ${ }^{19}$ The utilization of ANC services and in turn a favorable pregnancy outcome seen in the study could be because of better health care facilities, short distance to healthcare facilities, previous bad obstetric history and comparatively more literacy level of the mothers. Joshi et al found the proportion of LBW to be maximum $(61.76 \%)$ in mothers who did not receive any antenatal care followed by those who received inadequate care $(46.57 \%) .{ }^{15}$ Idris $\mathrm{MZ}$ et al in Lucknow observed highest incidence of low birth weight $(56.25 \%)$ among mother who did not receive any antenatal care, followed by $49.43 \%$ in those taking inadequate care (1-2 visits). ${ }^{20}$

Anemia has been identified as one of the important causes of LBW. One of the possible reasons for anaemia could be inadequate nutrition, lack of adequate knowledge about utilization of available antenatal care services, and recurrent infections. WHO has estimated the prevalence of anaemia in developed and developing countries in pregnant women as $14 \%$ and $51 \%$ respectively. ${ }^{21}$ Rohilla $\mathrm{M}$ et al in Chandigarh reported $33.33 \%$ small for gestational age neonates and $16.66 \%$ stillbirths among the mothers with severe anaemia $(<7 \mathrm{~g} / \mathrm{dl}){ }^{22}$

The rate of stillbirths among hypertensive mothers in the present study was also found to be similar to Yadav $\mathrm{S}$ et al, in New Delhi, who reported an overall incidence of adverse pregnancy outcomes as $14.8 \%$ in the hypertensive mothers. ${ }^{23}$ Among the diabetic mothers, it was found that low birth weight was prevalent in one fourth $(23.03 \%)$ cases. This figure was higher than 
quoted by Shefali AK et al $(12.3 \%)$ in Chennai. ${ }^{24}$ Any infection in the mother at any time during pregnancy was also significantly associated with adverse pregnancy outcomes. More than two third $(69.41 \%)$ of the mothers with any infection had delivered a low birth weight baby and $4.70 \%$ had a stillborn baby. The results were found to be in agreement with Idris MZ et al in Lucknow who observed highest incidence $(66.6 \%)$ of LBW among mothers who had significant acute infection during pregnancy. ${ }^{20}$

\section{CONCLUSION}

The present study confirms intra-uterine environment as a determinant for the final outcomes of pregnancy including the favourable as well as adverse outcomes. As there are several factors interacting in this phenomenon so it is not feasible to single out any particular factor affecting low birth weight and the potential importance of any factor in preventing LBW should be interpreted with caution as these may be interrelated. Henceforth, it is suggestive that a substantial reduction in LBW can be achieved by selectively targeting the reproductive age group females and educating them regarding the importance of antenatal care which is the pivotal factor affecting the pregnancy outcomes. Improved female education can thereby help in delaying the age at first pregnancy and encouraging wider intervals between births and universal coverage of adequate antenatal care for all the mothers especially the high risk ones. Discouraging early teenage marriages is also essential in order to reduce the burden of LBW babies.

\section{Recommendations}

Though the current health care system of our country is focusing towards improved antenatal care services and institutional deliveries, still we need to go a few steps further to strengthen these services by creating more awareness among the general population specifically the rural Indian population. This can be achieved by enhancing our information, education and communication activities and by providing better packages to the grass root level workers for motivating the mothers to utilize the available ANC services throughout their pregnancy, thereby yielding better maternal outcomes.

\section{Funding: No funding sources \\ Conflict of interest: None declared \\ Ethical approval: The study was approved by the Institutional Ethics Committee}

\section{REFERENCES}

1. United Nations Children's Fund. Maternal and Newborn Health. The State of The World's Children 2009;3-14.

2. Velankar D. Maternal factors contributing to low birth weight babies in an urban slum community of
Greater Mumbai. Bombay Hospital Journal. 2009;51(1):26-35.

3. World Health Organization. International statistical classification of diseases and related health problems, tenth revision, World Health Organization Geneva, 1992.

4. Viengsakhone L, Yoshida Y, Rashid H, Sakamoto J. Factors affecting low birth weight at four central hospitals in Vientiane. Lao Pdr Nagoya J Med Sci. 2010;72:51-8.

5. What works? A Review of the Efficacy and Effectiveness of Nutrition Interventions. Preventing Low Birthweight.Available at http:// www.adb.org/ publications/what-works-review-efficacy-andeffectiveness-nutrition-interventions. Accessed on 11 September 2001.

6. Rafati S, Borna H, Akhavirad MB, Fallah N. Maternal determinants of giving birth to low-birthweight neonates. Arch Iranian Med. 2005;8(4):27781.

7. Mccormick MC. The contribution of low birth weight to infant mortality and childhood morbidity. N Engl J Med. 1985;312:82-90.

8. Falkner F. Prevention in childhood of health problems in adult life, WHO, Geneva, 1980.

9. Development of a strategy towards promoting optimal fetal growth. World Health Organization. 2003.

10. National family health survey, India- NFHS-3 India. Summary of findings 2007. Available at URL; http://www.nfhsindia.org/NFHS-3\%20Data/VOL1/Summary\%20of\%20Findings\%20(6868K).pdf. Accessed on 7 June 2015.

11. Park K. Preventive medicine in obstetrics, paediatrics and geriatrics. Park's text book of preventive and social medicine, $23^{\text {rd }}$ Edition. M/S Banarsidas Bhanot Publishers. 2015;494.

12. Low birth weight and its consequences. Available from URL http:// wcd.nic.in/ research/nti1947/ 7.4\%20Low\%20\%20birth\%20weight $\% 203.2 \% 2020$ 08prema.pdf. Accessed on 5 October 2015.

13. WHO health for all. World health Organization SR. $21^{\text {st }}$ century; $4: 64$.

14. Kiran A, Garg BS. A study of factors affecting LBW. Indian J Community Med. 2000;25(2):57-61.

15. Joshi HS, Subba SH, Dabral SB, Dwivedi S, Kumar D, Singh S. Risk factors associated with low birth weight in newborns. Indian $\mathrm{J}$ Comm Med. 2005;30(4):142-3.

16. Sachdeva P, Patel BG, Patel B and Bhatt M. A study of factors affecting birth weight. J Global Pharma Technology. 2010;2(4):118-23.

17. National family health survey, India- NFHS-3 India. full report. Volume-I. 2007. Available from URL; http://www.nfhsindia.org/volume_1.Accessed on 4 November, 2014.

18. Saxena P, Salhan S, Chattopadhyay B, Kohli MPS, Nandan D, Adhish SV. Obstetric and perinatal outcome of teenage and older primigravidas- a 
retrospective analysis. Health and Population: Perspectives and issues. 2010;33(1):16-22.

19. Sharma AK, Chhabra P, Gupta P, Aggarwal QP, Lyngdoh T. Pregnancy in adolescents: a community based study. Indian J Prev Soc Med. 2003;34(1,2):24-32.

20. Demayer EM, Tegman A. Prevalence of anaemia in the world. World Health Organ Qlty. 1998;38:30216.

21. Idris MZ, Gupta A, Mohan U, Srivastava AK, Das V. Maternal health and low birth weight among institutional deliveries. Indian J Comm Med. 2000;25(4):156-60.

22. Rohilla M, Raveendran A, Dhaliwal LK, Chopra S. Severe anaemia in pregnancy: a tertiary hospital experience from northern India. J Obstet Gynaecol. 2010;30(7):694-6.
23. Yadav S, Saxena U, Yadav R, Gupta S. Hypertensive disorders of pregnancy and maternal and foetal outcome: a case controlled study. J Indian Med Assoc. 1997;95(10):548-51.

24. Shefali AK, Kavitha M, Deepa R, Mohan V. Pregnancy outcomes in pre-gestational and gestational diabetic women in comparison to nondiabetic women-a prospective study in Asian Indian mothers (CURES-35). J Assoc Physicians India. 2006;54:613-8.

Cite this article as: Saini S, Singh M, Mittal A. A study to assess the association of maternal factors and the outcome of pregnancy among mothers delivering in a tertiary care hospital in Haryana, India. Int $\mathbf{J}$ Community Med Public Health 2016:3:1716-22. 